\title{
Augmentation of Thermal Conductivity for Polypropylene / Ethylene-vinyl Acetate Based Composites Filled by Organic and Inorganic Particles
}

\author{
Rashed Al Mizan, Md. Aminul Islam \\ Materials and Metallurgical Engineering Department, BUET, Dhaka-1000, Bangladesh
}

Copyright@2018 by authors, all rights reserved. Authors agree that this article remains permanently open access under the terms of the Creative Commons Attribution License 4.0 International License

\begin{abstract}
Emerging thermal dissipation of many electronic devices, i.e. light emitting diodes, energy storage components, CPU chips etc. as well as in many emergent new applications (smart textile, self-assembling materials, etc.) is a great challenge. The reliance of thermal conductivity of composites on the filler loading, filler networking morphology and on the whole composite structure is also discussed. This work is intended to design composites for the improvement of thermal conductivity of polypropylene and ethylene-vinyl acetate copolymer with lower filler contents. As filler both organic (activated carbon) and inorganic (alumina) materials alone or in a combination of various relative proportions have been used. An internal blending unit was used for melting the copolymer and proper mixing the filler particles with the molten matrix. Final composites were made by the hot press. Then Lee's Disc apparatus was used to measure the thermal conductivity of various composite samples by steady-state method. Experimental results show that only carbon black addition was not adequate to increase the thermal conductivity of the composites to expected level. The experimental value compare with some theoretical model to describe the prediction value accuracy for such multiphase composite. However, addition of small amount of alumina powder with carbon black significantly increased the copolymer composites.
\end{abstract}

Keywords Composite Materials, Copolymer, Thermally Conductive Polymer, Cooling Curve, Prediction Model

\section{Introduction}

Thermal management is perilous to the performance, lifetime, and reliability of electronic devices. With the tininess, integration and functionalization of electronics and the emergence of new applications such as three-dimensional chip stack architectures, flexible electronics, and light emitting diodes, thermal debauchery becomes a challenging problem. Thus, particulate thermally-conductive materials are needed to help address this challenge. There are large number of particles are tremendously being used as additives in polymers to simultaneously enhance a variety of properties without sacrificing any qualities of the base polymer. Carbon black, activated carbon and alumina, for example, have very high potential in respect of thermal and electrical conductivities. As a consequence, these fillers can be used to alter thermally and electrically insulating polymer into conductive materials [1] and to increase their mechanical properties at the same time. Thermally conductive thermoplastics have many applications in the automobiles, aerospace, electronics, battery industries, thermal interface materials or heat sinks to dispel heat from electronic devices such as computers, flat panel displays, and cell phones [2-3]. There are many studies done on the particle size and content in the composite, determining the average interparticle space [4,5], which is close related to the thermal conductivity and mechanical properties. Moreover, it is a general trend, at same particle content, smaller particle size leads to lower interparticle space and more chances for the pattern of thermal conductive "network" [6-8]. The particle size and content affect the interparticle space and the stress state of the matrix polymer surrounding the voids. When the regular interparticle distance is in apt range, extensive plastic deformation in the matrix can be easily induced [9-10]. So the optimization of the particle size and content can be a suitable and viable way to prepare composites with good synthetic properties. [11]

This study is concerned with the thermal conductivity of the polymer micro-composite with particle content as minimum as possible. 


\section{Materials and Methods}

\subsection{Prediction Model for Effective Thermal Conductivity of Composites}

A large number of theoretical models for prediction of effective properties for multiphase materials have been developed, mainly because of the significance and interest in the effective thermal conductivity of multiphase system. For three-phase media, Woodside and Messmer [12] proposed the 'quadratic parallel' (QP) model for the effective conductivity, which are given by:

Woodside and Messmer model:

$$
\begin{gathered}
K_{e}=\left(\sqrt{K_{1}} \varphi_{1}+\sqrt{K_{2}} \varphi_{2}+\sqrt{K_{3}} \varphi_{3}\right)^{2} \\
K_{e}=\left(\sqrt{K_{i}} \varphi_{i}\right)^{2}
\end{gathered}
$$

Where $K_{e}$ is the thermal conductivities of composite, $K_{i}$, with $i=\{1,2,3\}$ is the conductivity of each phase and $\varphi_{i}$ the corresponding volume fraction. This model seems to be applicable when, $i>3$. Numerous weighted average models have also been projected for such multiphase mixtures .As per equation, this model based on the volume fraction and individual thermal conductivity of the system.

The Lewis-Nielsen model:

Other models such as the Lewis-Nielsen [13] model are based on particle size, geometry, and also it can derive to explain thermal conductivity of the hybrid nanocomposites [14], which can be represent by:

$$
K_{e}=K_{m}\left[\frac{1+\sum_{i=1}^{i=4} A_{i} B_{i} \varphi_{f i}}{1-\sum_{i=1}^{i=4} B_{i} \psi_{i} \varphi_{f i}}\right]
$$

Where

$$
\begin{gathered}
B_{i}=\frac{K_{f i} / K_{m}-1}{K_{f i} / K_{m}+A_{i}} \\
\psi_{i}=1+\left(\frac{1-\varphi_{m}}{\varphi_{m}^{2}}\right) \varphi_{f i}
\end{gathered}
$$

In Equation (3)(4)(5), $K_{m}, K_{f}$, are the thermal conductivity of the matrix and filler respectively, $\varphi_{f}$ is filler volume fraction with components $i=\{1,2,3\}$ for each particle, $\varphi_{m}$ is maximum filler volume fraction and $\mathrm{A}$ is shape coefficient for the filler particles [13].

New Thermal Conductive Model (Ji-Zhao Liang, Bo Zhu):

Liang and Zhu also develop [15] a model for thermal conduction in composite containing two filler. Their model consider the influence of the content of the filler particles and their arrangement formed in the matrix on the thermal conductivity of polymer multiphase composites .That is a thermal conductive element (i.e., unit cell) is formed periodically and repeat in the space of the polymer composites. The thermal conductivity $\left(k_{\text {eff }}\right)$ of the basic element or the polymer composites filled with two kinds of thermal conductive particles can be derived as follows:

$$
\begin{array}{r}
\text { Keff }=\frac{2}{\frac{1}{K_{e 1}}+\frac{1}{K_{e 2}}} \\
\text { Keff }=\frac{i}{\sum_{i=0}^{i} \frac{1}{K_{e i}}}
\end{array}
$$

Where

$$
\begin{gathered}
K_{e 1}{ }^{-1}=\frac{1-\sqrt[3]{\left(\frac{6 \varphi_{f 1}}{\Pi}\right)}}{K_{m}}+\frac{\sqrt[3]{\left(\frac{6 \varphi_{f 1}}{\Pi}\right)^{2}}}{K_{m}\left[\sqrt[3]{\left(\frac{6 \varphi_{f 1}}{\Pi}\right)}-\varphi_{f 1}\right]+K_{f 1} \varphi_{f 1}}(8) \\
K_{e 2}{ }^{-1}=\frac{1-\sqrt[3]{\left(\frac{6 \varphi_{f 2}}{\Pi}\right)}}{K_{m}}+\frac{\sqrt[3]{\left(\frac{6 \varphi_{f 2}}{\Pi}\right)^{2}}}{K_{m}\left[\sqrt[3]{\left(\frac{6 \varphi_{f 2}}{\Pi}\right)}-\varphi_{f 2}\right]+K_{f 2} \varphi_{f 2}}(9)
\end{gathered}
$$

In Equation (6), (7) (8), $\left(K_{e 1}\right),\left(K_{e 2}\right)$ are the thermal conductivity contributed by particle 1 and 2 respectively in the matrix, $K_{f}, \varphi_{f}, K_{m}$ describe earlier equation.

\subsection{Materials and Experimental Procedure}

\subsubsection{Materials Used}

Throughout the study Polypropylene(PP) homopolymer (Marlex ${ }^{\circledR}$ HGZ-120SP) that was purchased from Saudi Polymers Company which has a density of $0.904 \mathrm{~g} / \mathrm{cm}^{3}$, a thermal conductivity of $0.11 \mathrm{~W} / \mathrm{m} \mathrm{K}$. Also the EVA copolymer was Sipchem Ethylene vinyl acetate (EVA) 2018 has density of $0.935 \mathrm{~g} / \mathrm{cm}^{3}$ and thermal conductivity of $0.34 \mathrm{~W} / \mathrm{m} \mathrm{K}$. Two different fillers were used in the research, aluminium oxide (alumina) and activated carbon was obtained from Merck \& Sigma-Aldrich. As received, alumina had an average particle size of $63 \mu \mathrm{m}$ to $200 \mu \mathrm{m}$, thermal conductivity ranges from $30-40 \mathrm{~W} / \mathrm{m} \mathrm{K}$ and density is $3.94 \mathrm{~g} / \mathrm{cm}^{3}$. Whereas activated carbon had average particle size $\leq 100 \mu \mathrm{m}$ with thermal conductivity, density is $0.35-0.40 \mathrm{~W} / \mathrm{m} \mathrm{K}$ and $0.15-0.44 \mathrm{~g} / \mathrm{cm}^{3}$ respectively.

\subsubsection{Sample Preparation}

An internal mixer was used to disperse activated carbon and activated carbon/alumina mixtures in the PP/EVA matrix by melt mixing. Before melt mixing, the particle mixture is hand ground for $30 \mathrm{~min}$ in an internal granite 
mortar and all the materials were dried for 2 hours in an oven at $100^{\circ} \mathrm{C}$. To begin with, all compounds were mixed at $190^{\circ} \mathrm{C}$ in an internal mixer using a 30 -rpm mixing rate to insert sufficient shear rate to the mixer to ensure homogeneous mixing. The mixing procedure involved, adding the oven dried PP/EVA pellets into the preheated (at $190^{\circ} \mathrm{C}$ for $10 \mathrm{~min}$ ) mixer and keep the polymer pellets in the mixing chamber for $5 \mathrm{~min}$. Then, allowing the polymer to mix for 12 min with the addition of the particle. To obtain the desired samples, the composite, as obtained from the internal mixer, and then moulded into $90 \mathrm{~mm}$ diameter disc of 9mm thickness using a Fontunehy-draulic compression press at a load of approximately 30KN for 5 min at $190^{\circ} \mathrm{C}$ and then allowed to solidify by passing water through the hot press plate which then collect for the further test.
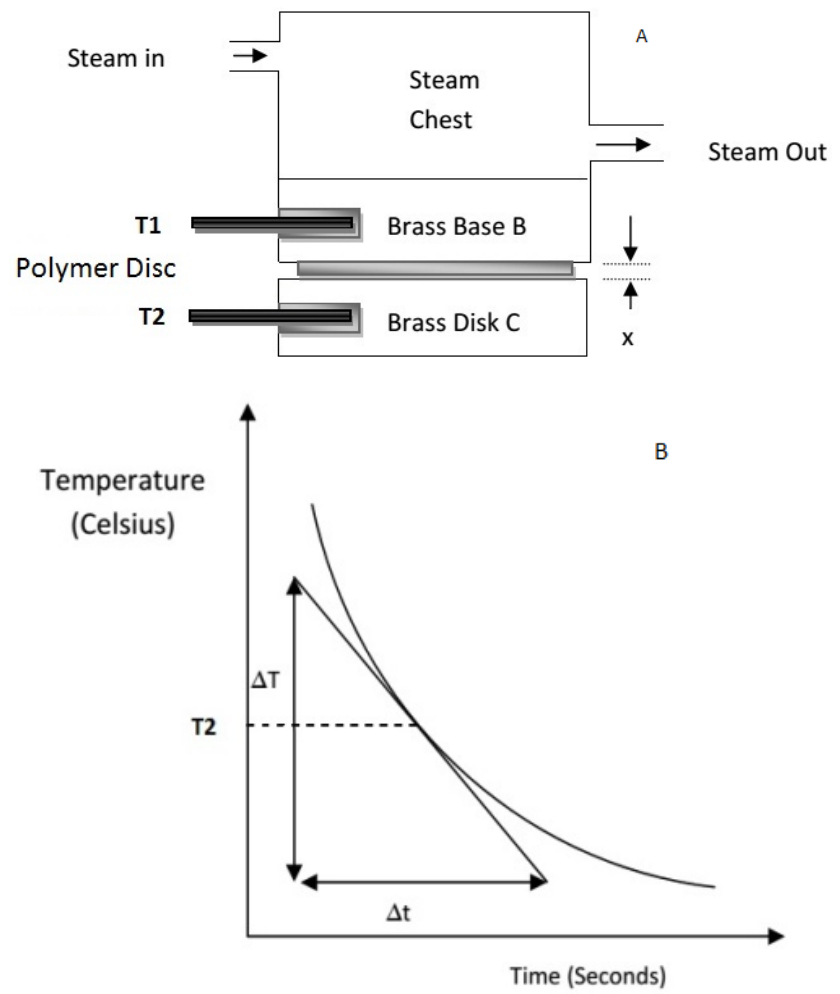

Figure 1. Concept of the experimental technique (A) Basic Concept of Test principle, (B) the temperature gradient measured and plot the cooling curve (Time versus Temperature)

\subsubsection{Characterization}

A high magnifying optical microscope was used to observe the morphology of the microcomposites, and to verify the expected particle dispersion. A steady-state heat-conduction technique similar to that described in ASTM D5470 standard was used to measure the thermal conductivities of the samples by Lee disc apparatus. The test was continued at room temperature of about $29^{\circ} \mathrm{C}$ and $90 \%$ R.H. If ' $K$ ' is the thermal conductivity of the sample, A is the cross-sectional area of the sample having a radius ' $r$ ' and $(\mathrm{T} 1-\mathrm{T} 2)$ is the temperature difference across the sample thickness ' $x$ ' (Figure 1A) (Upper disk, T1 and Lower Disk, T2).Recorded the temperature varienece of the Brass disc with a time of cooling was plotted as shown in (Figure 1B). A tangent is drawn at the steady state temperature $\mathrm{T} 2$ from where slope (dT/dt) found. Thus from above value thermal conductivity can be calculated by (10), where mass and specific heat of the lower disc (C) is $m$ and s.

$$
K=m s \frac{m s(d T / d t) x}{A(T 1-T 2)}
$$

\section{Results and Discussion}

\subsection{Dispersal of Multi Particle in the PP/EVA Matrix}

During the study binary matrix system of Polypropylene (PP)/Ethylene vinyl acetate (EVA) was used in different weight \% where in combination PP and particle have 60wt $\%$ and EVA has $40 \mathrm{wt} \%$, the composite composition shown in Table 1. The samples were designed in such a way, to observe single particle effect to binary particle effect on thermal conductibility of the composite. The distribution of the particles varies with particle content and particle size, which determines the properties of the composites. [16]

Table 1. The elemental data of various composite

\begin{tabular}{|c|c|c|c|c|c|}
\hline \multirow{2}{*}{$\begin{array}{c}\text { Sample } \\
\text { ID }\end{array}$} & \multicolumn{2}{|c|}{$\begin{array}{c}\text { Matrix system } \\
\text { (wt\%) }\end{array}$} & \multicolumn{2}{|c|}{ Particle content(wt\%) } & \multirow{2}{*}{$\begin{array}{c}\text { Sum of } \\
\text { filler } \\
\text { (wt\%) }\end{array}$} \\
\hline & PP & EVA & $\begin{array}{l}\text { Activated } \\
\text { Charcoal } \\
\text { (Carbon) }\end{array}$ & $\begin{array}{c}\text { Alumina } \\
\left(\mathrm{Al}_{2} \mathrm{O}_{3}\right)\end{array}$ & \\
\hline 1 & 100 & 0 & 0 & 0 & 0 \\
\hline 2 & 54 & 40 & 6 & 0 & 6 \\
\hline 3 & 52 & 40 & 8 & 0 & 8 \\
\hline 4 & 54 & 40 & 3.6 & 2.4 & 6 \\
\hline 5 & 54 & 40 & 2.4 & 3.6 & 6 \\
\hline 6 & 54 & 40 & 1.2 & 4.8 & 6 \\
\hline
\end{tabular}

The composites surfaces were inspected by Optical microscope, From Figure 2, for a certain size of the particle, the dispersion in the composite changes with content. Their trends are similar when the particle is similar (Figure $2 \mathrm{~A}-\mathrm{C}$ ) but when the binary particle composition is used the distribution pattern is changed (Figure 2C). Sample 2, 3 and 6 taken as a typical example to show the influence of content on the dispersion (Figure $2 \mathrm{~A}-\mathrm{C}$ ). The carbon content of sample 1(Figure 2A), the particle is dispersed in the matrix tends to aggregate which is increased with the increase of content (Figure 2A-B) and the interparticle distance will be lower to create a continuous network. The alumina particles are mostly separated without contacting each other at the lower content in binary particle 
arrangement rather than they create contact between carbon particles. In sample 6 when the alumina content increases in a binary system of PP/EVA matrix (Figure 2C), the average interparticle distance gets smaller, and agglomerates are formed resulting in the formation of the alumina network, of course, interpolymer layers exist among the particles. The black and grey marks were added to the Optical microscope pictures to indicate the local $\mathrm{Al}_{2} \mathrm{O}_{3}$ network contacting by carbon particle (Figure 2C).

\subsection{The Thermal Conductivity of the Composite}

Figure 3(A-F) shows the thermal conductivity curves with a different weight content of particle with regression analysis. Table 2, represent the different value of cooling curve which is used to calculate ultimate thermal conductivity. In addition, the values show excellent regression percentile which is in between $80 \%$ - 90\%, which clearly indicate the experimental consistency in the testing environment of about $29^{\circ} \mathrm{C}$ and $90 \%$ R.H.

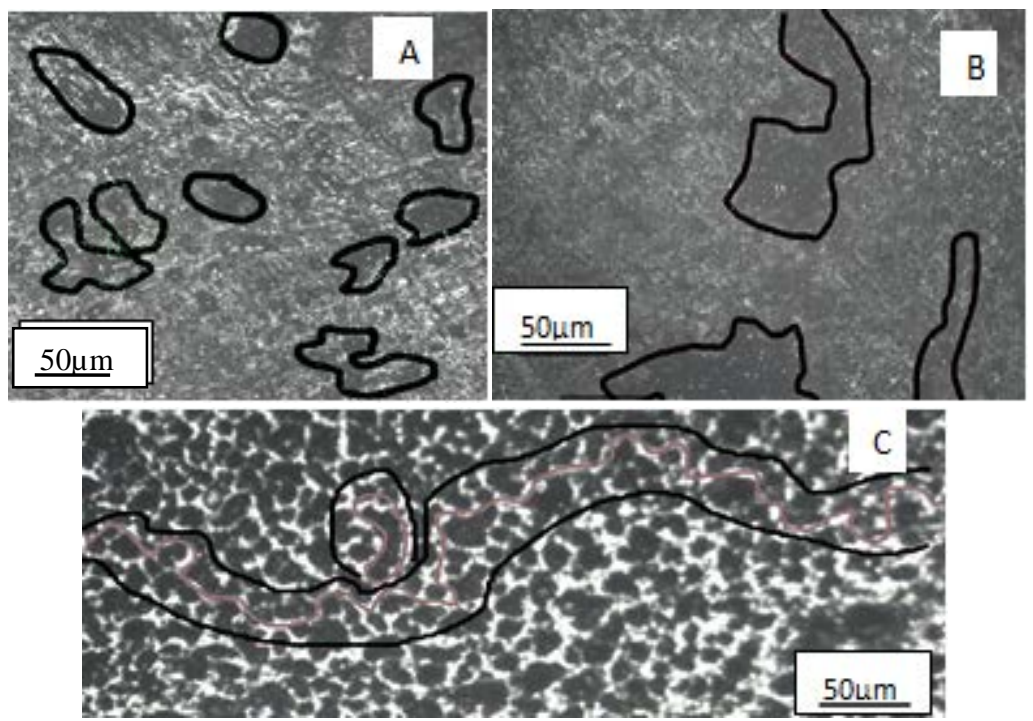

Figure 2. Optical micrographs of surfaces of PP/EVA/ $/ \mathrm{Al}_{2} \mathrm{O}_{3} /$ Carbon composites: (A) Sample 2 (B) Sample 3 (C) Sample 6 in high magnifications. The black and grey marks are added to emphasize the local network of the samples.

Table 2. Measured different values of cooling for developed composites

\begin{tabular}{|c|c|c|c|c|c|}
\hline $\mathrm{s}$ & $\begin{array}{c}\text { Steady State Temperature } \\
\left(\mathrm{T}_{2}\right)\end{array}$ & $\begin{array}{c}\text { Difference of Temperature } \\
\left(\mathrm{T}_{1}-\mathrm{T}_{2}\right)\end{array}$ & $\begin{array}{c}\text { Least } \\
\text { Squares( } \mathrm{R}^{2} \text { of Curve }\end{array}$ & $\begin{array}{c}\text { Regression Value Fit Percent } \\
\text { With Experimental }\end{array}$ & $\begin{array}{c}\text { Slope Of Cooling } \\
\text { Curve (dT/dt) }\end{array}$ \\
\hline 1 & 54 & 25 & 0.8944 & 89 & 0.00711 \\
\hline 2 & 56 & 14 & 0.8991 & 89 & 0.01227 \\
\hline 3 & 56 & 19 & 0.9146 & 91 & 0.0087 \\
\hline 4 & 59 & 13 & 0.8296 & 83 & 0.0073245 \\
\hline 5 & 61 & 11 & 0.8414 & 84 & 0.012105 \\
\hline 6 & 63 & 7 & 0.8551 & 85 & 0.01785 \\
\hline
\end{tabular}



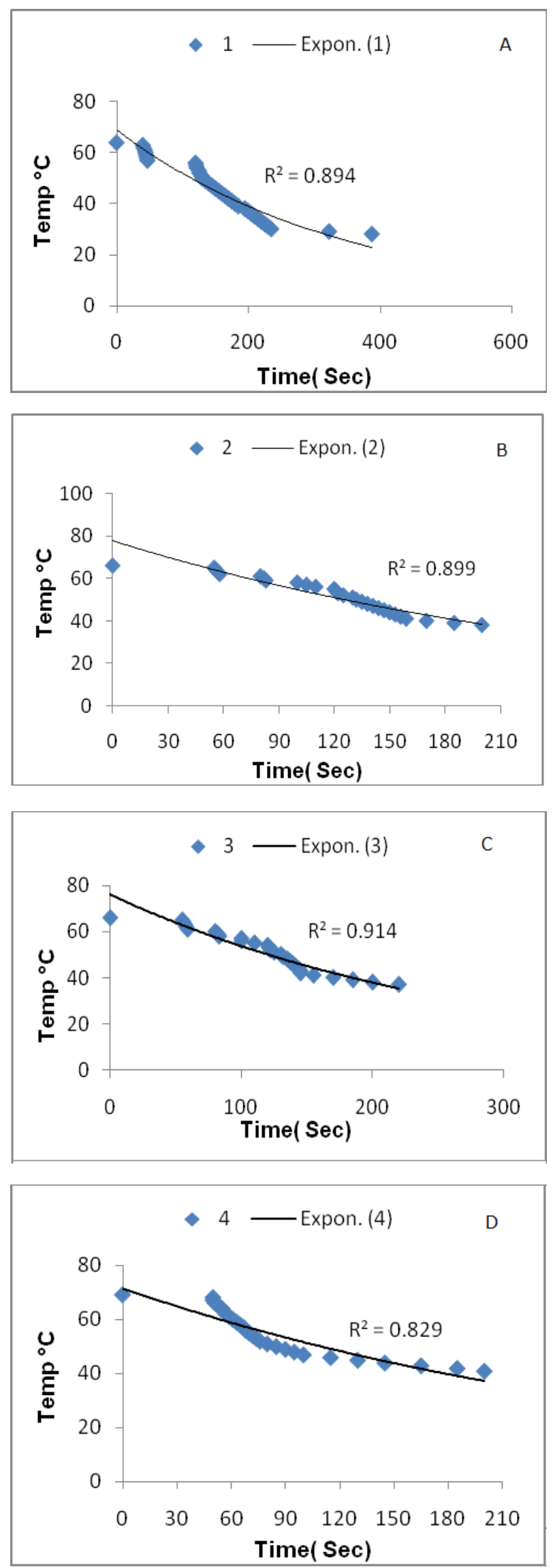
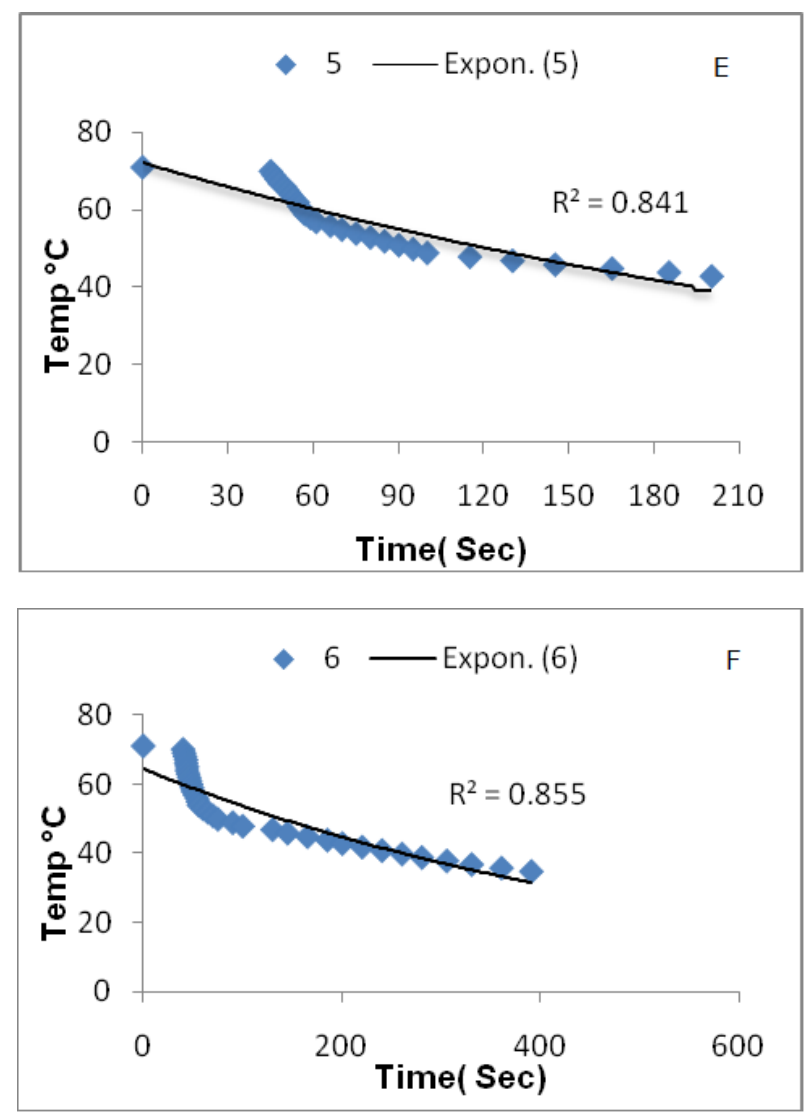

Figure 3. Cooling rate for composite (Time -Temperature curve) with regression analysis: A) Sample 1 B) Sample 2 C) Sample 3 D) Sample 4 E) Sample 5 F) Sample 6

Thermal conductivities of all composites increase with the increase of relative filler content of two filler in a fixed wt\%. In Figure 4(A) the thermal conductivity increases with the increase of carbon filler content, this increase might have been attributed due to continuous pathway created in the composites which are greater in sample 3 than sample 2. However, the support of continuous pathway creation was shown in Figure 2A, the black mark for sample 2 and the black/grey mark for sample 3 in Figure 2B. This will prove that the isolated particles have little effect on the enhancement of the thermal conductivity until the particle form a continuous pathway through the matrix. Moreover, the shape of carbon particle assumed to be spherical while in actual practice they are irregular shaped. As lower filler content is the main purpose of this study, so lower content carbon sample 2 taking into consideration.

In Figure 4(B) shows the effect of relative particle content on thermal conductivity of carbon and alumina in a fixed wt $\%$ of $6 \%$ where thermal conductivity increase with the increase of alumina content in the binary particle system. Initially, in sample 4, thermal conductivity increases slightly with the previous composite due to isolated alumina particle aggregation which can only create contact between carbon particle resulting acceleration of creating a continuous network of carbon particle in PP/EVA matrix.However, the scenario will change for 
sample 5 and 6 when the alumina content increases in the fixed weight of $6 \%$. From Figure 2C, it is clear that the higher alumina content in sample 6 creates a continuous network which gives a higher thermal conductivity of the composite. From the Figure $2 \mathrm{C}$ it is also clear that the carbon particle creates a contact between the alumina networks which also accelerate thermal conductivity. This is why; we found a shifting of thermal conductivity at sample 6.
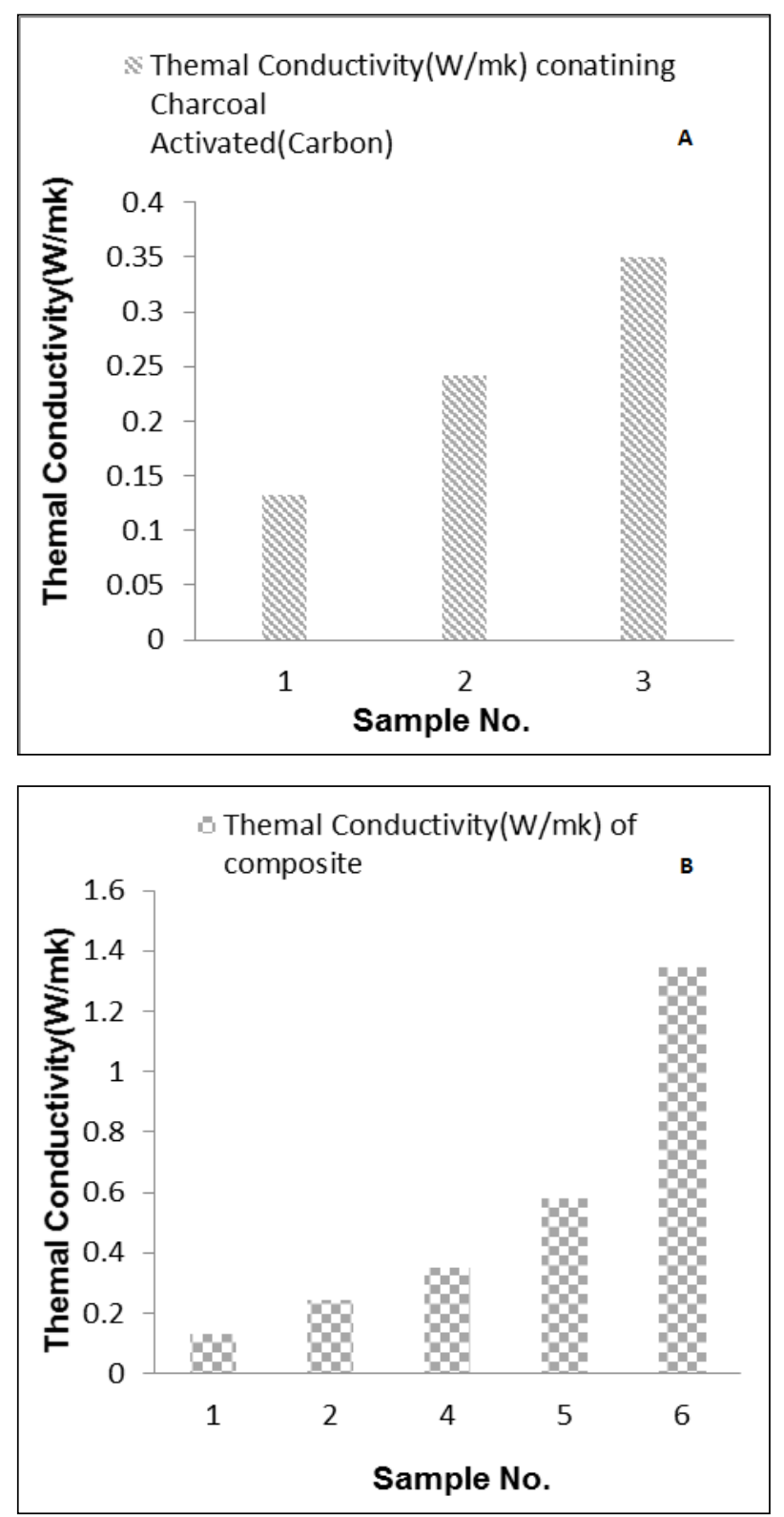

Figure 4. Thermal conductivity of PP/EVA composites as a function of filler content; show thermal conductivity increase with the increase of a) carbon particle content and b) carbon/alumina particle content

\subsection{Experimental Values Comparison with Theoretical Prediction}

Figure5 compares experimental data for the micro composites made with randomly oriented filler in PP/EVA with a variety of theoretical predictions and Table 3 shows the respective data. All the data used in simulation are taken according to volume fraction of individual element of the composite which calculates by the respective weight of particle used in matrix with consideration of respective element density, see sec. 2.2.1. Table 4 shows related calculated data for element wt\% to vol\% where sample1 are avoided for neat PP. Moreover, all the graph shown in paper according to Sample No. vs Function, so the simulation and experimental data are merged in the graph.As throughout the study, particle wt\% was fixed and vol\% was $<16 \%$, however it is noticed that the experimental results and all three models are close to each other at single filler content with higher vol\% for sample 2.It is also revealed that all three models give a constant prediction of thermal conductivity for sample 2-sample 6 . This is happen due to consider all coefficient of particle related to mixing and shape are constant, as the particle assume as sphere and random closely distributed in the composite. Whenever the experimental values shows increasing trend of thermal sample 1 - sample 6 . It is also observed from the comparison of experimental and predicted data, the prediction model is more useful whenever a successive increase of particle content in matrix than the fixed particle content [12]. It is further noted that all there underestimates with respect to the experimental data. As the predicted data follow a common trend, so this will prove the amendment strength of experimental data and technique, which discuss earlier in sec 4.1 However, none of the models provided a satisfactory prediction of thermal conductivity. This may be due to the micro composite, attributed to their sufficient surface area which results in a large contact network (Figure 2) between particle to particle in matrix which reduce the interfacial resistance to heat flow between the particle to particle and the matrix material which ensure complete bonding and phonon acoustic match [12, 17], ultimately increase thermal conductivity in practically. It has also been noted that the thermal conductivities obtained from experiments and three theoretical models generally exhibited increases with increase in the volume fraction of alumina $\left(\mathrm{Al}_{2} \mathrm{O}_{3}\right)$ from sample 4-sample 6 . 
Table 3. Thermal Conductivity values of hybrid composites and comparison with theoretical prediction

\begin{tabular}{|c|c|c|c|c|}
\hline \multirow{2}{*}{$\begin{array}{c}\text { Sample } \\
\text { Name }\end{array}$} & Woodside and Messmer Model & The Lewis-Nielsen model & New Model(Ji-Zhao Liang) & Experimental \\
\cline { 2 - 5 } & 0.13 & 0.13 & 0.13 & 0.132626729 \\
\hline 1 & 0.223 & 0.1004 & 0.113 & 0.241491375 \\
\hline 2 & 0.227 & 0.1074 & 0.122 & 0.46222401 \\
\hline 3 & 0.233 & 0.0930 & 0.103 & 0.486826115 \\
\hline 4 & 0.239 & 0.0896 & 0.102 & 0.580374179 \\
\hline 5 & 0.228 & 0.0966 & 0.1024 & 1.344857143 \\
\hline 6 & & &
\end{tabular}

Table 4. Related conversion data for comparison with theoretical prediction

\begin{tabular}{|c|c|c|c|c|c|c|c|c|}
\hline \multirow{2}{*}{$\begin{array}{c}\text { Sample } \\
\text { Name }\end{array}$} & \multicolumn{3}{|c|}{ PP } & \multicolumn{2}{c|}{ EVA } & \multicolumn{2}{c|}{ Carbon } & \multicolumn{2}{c|}{ Alumina } \\
\cline { 2 - 10 } & $\mathrm{Wt} \%$ & $\mathrm{Vol} \%(\Phi)^{*}$ & $\mathrm{Wt} \%$ & $\mathrm{Vol} \%(\Phi)^{*}$ & $\mathrm{Wt} \%$ & $\mathrm{Vol} \%(\Phi)^{*}$ & $\mathrm{Wt} \%$ & $\mathrm{Vol} \%(\Phi)^{*}$ \\
\hline 2 & 54 & 51.49527006 & 40 & 38.47189628 & 6 & 12.26291694 & 0 & 0 \\
\hline 3 & 52 & 48.4737 & 40 & 36.46087 & 8 & 16.35056 & 0 & 0 \\
\hline 4 & 54 & 53.71808748 & 40 & 38.47189628 & 3.6 & 7.357750164 & 2.4 & 0.547785122 \\
\hline 5 & 54 & 54.86271 & 40 & 38.4719 & 2.4 & 4.905167 & 3.6 & 0.821678 \\
\hline 6 & 54 & 52.52771129 & 40 & 38.47189628 & 1.2 & 9.810333551 & 4.8 & 0.273892561 \\
\hline
\end{tabular}

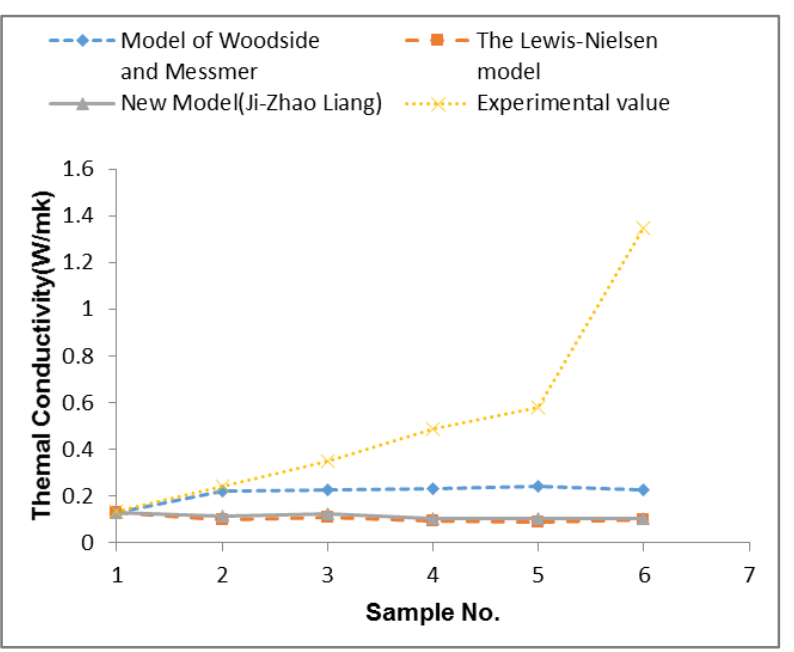

Figure 5. Comparison of experimental values of thermal conductivity of PP/EVA based composite with theoretical prediction value

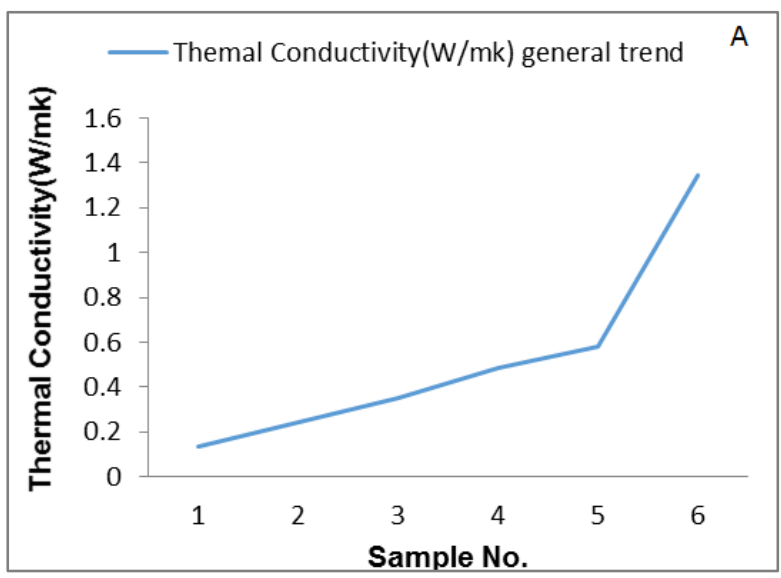

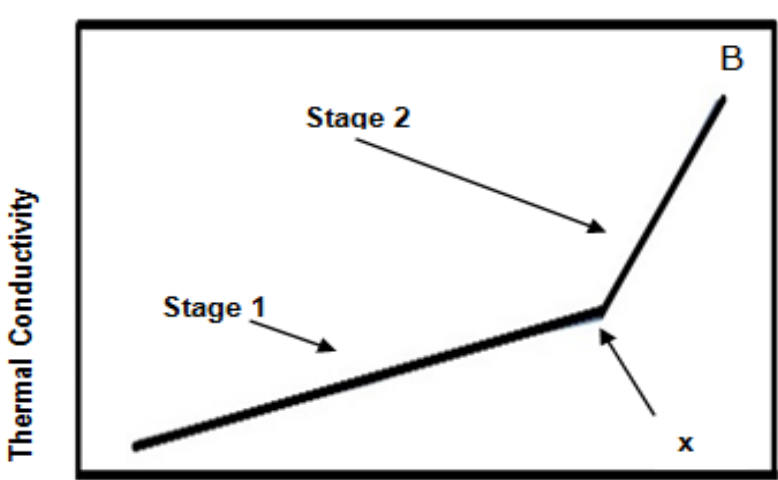

Figure 6. (A) Thermal conductivity into two stages with function of relative particle content (B) Abstract view

The curves can be model into two stages Figure 6(A-B). The thermal conductivity increases more rapidly in the second stage than in the first stages. The turning point in Figure 6(B-x) from stage 1 to stage 2 appears at medium alumina content of sample 5 . The first stage includes sample 1-5, in which most alumina dispersed separately rather than creating a continuous pathway in PP/EVA matrix with carbon particle, so the thermal conductivity increases slowly with content. The abrupt shifting of the conductivity of the second stage indicates the formation of the continuous pathway of the particle [12]. There is also a general relationship of thermal conductivity can be developed in respect of sample 1 . In Table 5, this relative increase of thermal conductivity is shown where sample 6 gain highest $90 \%$ increasing than sample 1 which is 10 times higher than sample 1's thermal conductivity. This can be represented in Figure 7(A). Furthermore, there is also a representation of the relative increasing percentage of a composite sample to next one will be present in Table 5 . 
Table 5. Thermal conductivity values and relative comparison of composites

\begin{tabular}{|c|c|c|c|}
\hline Sample Name & $\begin{array}{c}\text { Experimental Thermal Conductivity } \\
\text { (T.C) (W/m-k) }\end{array}$ & $\begin{array}{c}\text { Increasing T.C \% To Neat } \\
\text { Polypropylene }\end{array}$ & $\begin{array}{c}\text { Relative Increasing \% of T.C In } \\
\text { Successive Order of Sample }\end{array}$ \\
\hline 1 & 0.132626729 & 0 & 0 \\
\hline 2 & 0.241491375 & 45.0801385 & 94.6 \\
\hline 3 & 0.46222401 & 71.30682825 & 51.6 \\
\hline 4 & 0.486826115 & 72.75685818 & 16 \\
\hline 5 & 0.580374179 & 77.1480652 & 131 \\
\hline 6 & 1.344857143 & 90.1382292 & \\
\hline
\end{tabular}

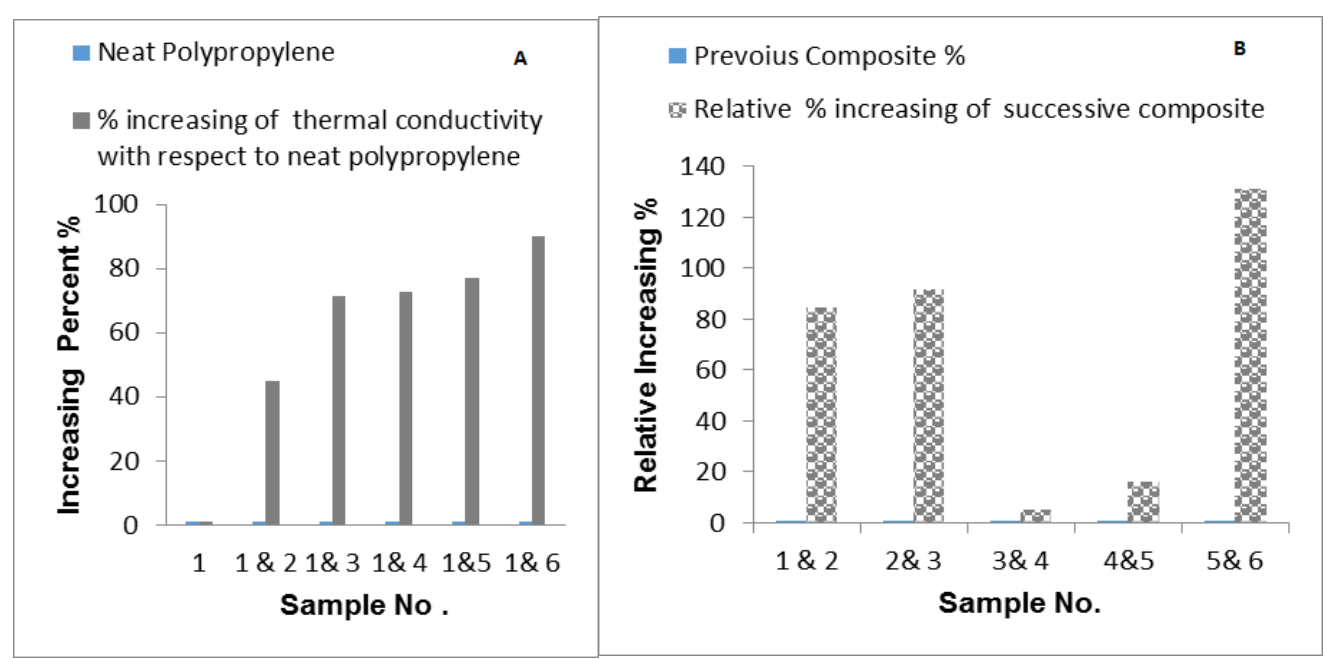

Figure 7. (A) Increasing of thermal conductivity with respect to neat polypropylene (B) Relative increasing of thermal conductivity between successive samples

From Figure 7(B), it can say that sample 1,2 and sample 2, 3 give a good relative increase but sample 3,4 and sample 4,5 don't which previously explain in sec 3.2. However, sample 5,6 give the excellent relative increase among all. So from that, it can point out that in this binary particle system, the inclusion of single particle (sample 2,3) will increase conductive properties where as the inclusion of double particle $(4,5)$ initially slow down the conductivity propagation but finally it gives a larger shift (sample 6) in conductivity increase.

\section{Conclusions}

After detail experimental study on polymer microcomposite containing organic (charcoal activated) and inorganic (alumina) filler the result is summaries as below.

a. The microcomposite containing single filler have lower effect on thermal conductivity of polymer micro composite than binary particle.

b. The alumina particle can form thermal conductive alumina pathway more easily than carbon particle in binary matrix PP/EVA by binary particle $\mathrm{C} / \mathrm{Al}$ composite. However, at lower alumina content this pathway creation is isolated than in higher alumina content in the polymer microcomposite. c. It is noted that the theoretical model are not sufficient to predict the thermal conductivity values for composite having fixed weight fraction of particle which have similar geometry and dispensability in the matrix.

d. It is revealed from experimental result that copolymer EVA will help to homogeneous mixing of particle in micro composite, resulting to create thermal conductive pathway of filler.

e. The ultimate thermal conductivity of this study is nearly ten times of the pure PP in at $6 \mathrm{wt} \%$ of filler in the binary matrix system. The present study would provide practical and theoretical supports for thermal conductive polymer composites with good synthetic properties.

Due to enhance thermal conductivity, this study will help to design further research work in the development of conductive nanocomposite as well as micro composite. This data can assist to develop microelectronic, nano-electronics, structural battery, smart fiber and thermal sensor which all have a big economic potential.

\section{Acknowledgements}

The Project Director would like to express his gratitude of CASR, BUET to provide necessary funding for this 
research work. He also indebted to MME Department for ensuring access to all laboratories and equipment required for the research project.

\section{REFERENCES}

[1] Breuer O, Sundararaj U. Big returns from small fibers: a review of polymer/carbon nanotube composites. Polymer composites. 2004 Dec 1; 25(6):630-45.

[2] Njuguna J, Pielichowski K. Polymer nanocomposites for aerospace applications: properties. Advanced Engineering Materials. 2003 Nov 1; 5(11):769-78.

[3] Prasher RS, Chang JY, Sauciuc I, Narasimhan S, Chau D, Chrysler G, Myers A, Prstic S, Hu C. Nano and Micro Technology-Based Next-Generation Package-Level Cooling Solutions. Intel Technology Journal. 2005 Nov 1; 9(4).

[4] Wu S. A generalized criterion for rubber toughening: the critical matrix ligament thickness. Journal of Applied Polymer Science. 1988 Feb 5; 35(2):549-61.

[5] Bartczak Z, Argon AS, Cohen RE, Weinberg M. Toughness mechanism in semi-crystalline polymer blends: II. High-density polyethylene toughened with calcium carbonate filler particles. Polymer. 1999 Apr 30; 40(9):2347-65.

[6] Voet A. Temperature effect of electrical resistivity of carbon black filled polymers. Rubber Chemistry and Technology. 1981 Mar; 54(1):42-50.

[7] Foulger SH. Electrical properties of composites in the vicinity of the percolation threshold. Journal of Applied Polymer Science. 1999 Jun 20; 72(12):1573-82.

[8] Ling W, Gu A, Liang G, Yuan L. New composites with high thermal conductivity and low dielectric constant for microelectronic packaging. Polymer Composites. 2010 Feb.
1; 31(2):307-13.

[9] Kim GM, Michler GH. Micromechanical deformation processes in toughened and particle-filled semicrystalline polymers: Part 1 . Characterization of deformation processes in dependence on phase morphology. Polymer. 1998 Nov. 30; 39(23):5689-97.

[10] Wu S. Phase structure and adhesion in polymer blends: a criterion for rubber toughening. Polymer. 1985 Nov. 1; 26(12):1855-63.

[11] Foulger HS, Gregory R. Intelligent textiles based on environmentally responsive fibers. National Textile Center Research Briefs-Materials Competency. 2001.

[12] Fedaoui, Kamel, Salah Madani, and ToufikKanit. "Prediction of Effective Thermal Conductivity of Heterogeneous Random Multi-Phase Composites." Upb Sci. Bull. Ser. D. 78 (2016).

[13] Agarwal, Sushant, M. Masud K. Khan, and Rakesh K. Gupta. "Thermal conductivity of polymer nanocomposites made with carbon nanofibers." Polymer Engineering \& Science 48.12 (2008): 2474-2481.

[14] Weber, Erik H., Matthew L. Clingerman, and Julia A. King. "Thermally Conductive Nylon 6, 6 and Polycarbonate Based Resins. I. Synergistic Effects of Carbon Fillers." Journal of Applied Polymer Science 88.1 (2003): 112-122.

[15] Liang, Ji-Zhao, and Bo Zhu. "Estimation of thermal conductivity of polymer multiphase composites." Polymer Engineering \& Science 57.9 (2017): 965-972.

[16] Zhang, S., Et Al. "The Effects of Particle Size and Content on the Thermal Conductivity and Mechanical Properties of $\mathrm{Al}_{2} \mathrm{O}_{3} /$ High Density Polyethylene (Hdpe) Composites." Express Polymer Letters 5.7 (2011).

[17] Prasher, Ravi S., Et Al. "Thermal Resistance of Particle Laden Polymeric Thermal Interface Materials." Transactions-American Society of Mechanical, 125(6) (2003), 1170-1177. 